\title{
A GESTÃO AMBIENTAL A PARTIR DO ORÇAMENTO PÚBLICO: UMA ANÁLISE DAS DESPESAS REFERENTES AO ORÇAMENTO DO MUNICÍPIO DE SÃO JOÃO DA BARRA
}

\author{
ENVIRONMENTAL MANAGEMENT FROM THE PUBLIC BUDGET: AN ANALYSIS \\ OF THE EXPENSES RELATING TO THE BUDGET OF THE MUNICIPALITY OF SÃO \\ JOÃO DA BARRA, RIO DE JANEIRO STATE, BRAZIL
}

Resumo: A gestão ambiental consiste numa função dentro da legislação orçamentária, cuja finalidade se refere ao planejamento das políticas públicas ambientais. Neste caso, ao analisar os dados acerca desta função, é possível identificar para quais áreas ambientais se volta a ação governamental. Desta forma, o objetivo deste trabalho consiste em identificar como o município de São João da Barra tem gerido, a partir do orçamento público, a gestão ambiental. Para tanto, a metodologia pautouse no levantamento de dados realizados no sistema de transparência dos governos federal e municipal, levando em consideração a execução do Plano Plurianual municipal (2014-2017). Neste período, destacaram-se a distância entre o valor planejado e o realizado nas ações orçamentárias, além da queda de execução do ano de 2014 para 2015 e 2016. Outro ponto a ser considerado consiste no montante do gasto executado e na ausência de prioridade da gestão ambiental num cenário municipal marcado pelo aumento da exploração dos recursos naturais e dos recursos financeiros dele provenientes

Palavras-Chave: Gestão Ambiental Pública. Orçamento Público. Ação Governamental e Políticas Públicas.

\section{Sandra Rangel de Souza Miscali}

Doutorando em Políticas Sociais pela Universidade Estadual do Norte Fluminense Darcy Ribeiro. Coordenadora Executiva da Associação Raízes. sandramiscali@gmail.com

\section{Rachel Carvalho}

Doutoranda em Democracia no Século XXI pela Universidade de Coimbra.rachelcarv@gmail.com

Isroberta Rosa Araujo

Mestre em Políticas Sociais pela Universidade Estadual do Norte Fluminense Darcy Ribeiro. Pesquisadora Social da Associação Raízes. isroberta@hotmail.com
Abstract: Environmental management constitutes a function within budgetary legislation, and its purpose is the planning of public environmental policies. In such case, by analyzing data about this function, it can be identified to which environmental areas government action is being taken. Accordingly, this work seeks to identify how the municipality of São João da Barra has managed environmental management from the public budget. For this, the methodology was guided by the data survey conducted in the transparency system of the federal and municipal governments, considering the implementation of the municipal Multi-year Plan (2014-2017). In this period, the gap between the planned and the executed amount in the budget actions was pointed out, as well as the drop in execution from 2014 to 2015 and 2016. Another issue to consider is the amount of expenditure executed and the lack of priority for environmental management in a municipal scenario marked by increased exploitation of natural resources and the financial resources derived from it.

Keywords: Public Environmental Management. Public Budget. Government Action and Public Policies.

Fabiana Arruda Resende Reis

Mestre em Políticas Sociais pela Universidade Estadual do Norte Fluminense Darcy Ribeiro. Assessora de Coordenação da Associação Raízes. fabi_sjdr@yahoo.com.br

Kíssila Neves Soares Vitorino

Doutoranda em Sociologia Política pela Universidade Estadual do Norte Fluminense Darcy Ribeiro e professora do Instituto Federal de Minas Gerais. kissila.neves@ifsudestemg.edu.br 


\section{Introdução}

O sistema capitalista preconiza a utilização de recursos naturais em detrimento do desenvolvimento econômico, bem como produz uma série de desigualdades socioambientais. Quintas (2009) questiona se há crise ambiental ou do próprio modelo civilizatório, à medida que $20 \%$ do contingente mais rico da população mundial são responsáveis por $86 \%$ de todo o consumo privado no Planeta, enquanto os $20 \%$ mais pobres consomem apenas 5\% (PNUMA, 2002).

Neste sentido, podemos refletir sobre o papel e a gestão do Estado enquanto formulador, executor e regulador de políticas públicas socioambientais, que visam o bem-estar de toda a sociedade. Para isso, o presente estudo objetiva identificar como o município de São João da Barra tem administrado, a partir do orçamento público, a gestão ambiental.

Tendo em vista que o orçamento público consiste no instrumento utilizado pelos governos para planejar a utilização do dinheiro arrecadado com os tributos (impostos, taxas, contribuições de melhoria, entre outros) a fim de desenvolver políticas públicas, tornase necessário analisar a execução orçamentária para assim compreender as consideradas, pela gestão pública, como prioritárias.

Uma vez que o orçamento estima as receitas e fixa as despesas, por meio do sistema de transparência, é possível monitorar os gastos públicos e as prioridades atendidas pelo governo, executadas anualmente. Desta forma, ao final de quatro anos, é possível analisar como a gestão municipal administrou os recursos e as políticas públicas.

A fim de averiguar a gestão pública ambiental no governo municipal, em um primeiro momento, se discorrerá sobre a formação da agenda de políticas públicas em nível nacional; posteriormente, se examinará a composição das políticas ambientais com foco no orçamento; e, por fim, será analisada a execução das políticas públicas de gestão ambiental do município de São João da Barra. 


\section{Metodologia}

A partir do método quantitativo, o modelo de investigação sobre a gestão ambiental construído levou em consideração o pressuposto de que existem gastos públicos realizados na área pelos entes federativos. Ainda, o modelo visou analisar como estes se desenvolveram na última gestão do Plano Plurianual (20142017) no município de São João da Barra.

Em decorrência da ausência de disponibilidade de informações em uma única fonte, foram utilizadas as bases de dados do portal de Transparência do Governo Federal, município de São João da Barra, e do Tribunal de Contas do Estado do Rio de Janeiro.
A análise dos dados desenvolveu-se a partir das funções ${ }^{1}$ e subfunções ${ }^{2}$ elencadas na Portaria no 42/1999 do Ministério do Orçamento e Gestão ${ }^{3}$, conforme Tabela 1.

Os dados foram tabulados, no programa Excel, por ano, função e subfunção, e analisados com o objetivo de identificar o orçamento planejado, as despesas anuais executadas (quantitativo, crescimento e diminuição) e as prioridades governamentais nos campos da gestão ambiental pública.

Destaca-se que o presente artigo representa uma versão preliminar do estudo em curso, tendo em vista a ampliação das análises para as demais categorias do orçamento: natureza de despesa, programa, ação orçamentária e fonte dos recursos.

\section{Quadro 1 - Função e subfunção referentes à Gestão Ambiental}

\begin{tabular}{|c|c|}
\hline FUNÇÃo & \multicolumn{1}{c}{ SUBFUNÇÃo } \\
\hline & 541 - Preservação e Conservação Ambiental \\
& 542 - Controle Ambiental \\
\hline $\mathbf{1 8}$ - GESTÃo AMBIENTAL & 543 - Recuperação de Áreas Degradadas \\
& 544 - Recursos Hídricos \\
& 545 - Meteorologia \\
\hline
\end{tabular}

Fonte: Portaria n 42/1999 do Ministério do Orçamento e Gestão

\section{A QUALIDADE DE ENSINO QUE VOCE JÁ GOWHECE.}

INSCREVA-SE AGORA!

口 PRESENCIAL

口 SEMIPRESENCIAL

口 EAD 


\section{As políticas públicas ambientais brasileiras}

A seguir, podemos identificar como o Estado assumirá funções de executor - responsabilidades na elaboração e implementação de políticas, programas e projetos - e regulador das políticas ambientais, à medida que crie uma série de ferramentas regulatórias para sanção, apoio ou ameaça (WINDHOLZ; HODGE, 2013, p. 22).

Nas décadas de 1930 a 1960, não havia propriamente uma política ambiental no Brasil, ou uma instituição gestora da temática ambiental. Havia políticas setoriais que consideravam tangencialmente a questão ambiental, tendo como foco a exploração dos recursos naturais

A construção das políticas ambientais brasileiras é influenciada diretamente pelos eventos internacionais, 0 que acarretará sua construção no período ditatorial, antes da promulgação da Carta Magna de 1988. No campo normativo, as décadas de 1990 e 2000 foram profícuas para a elaboração de várias legislações regulamentadoras das políticas ambientais.

\section{Tabela 1: Marcos da Política Ambiental no Brasil}

\begin{tabular}{|c|c|c|}
\hline Ano & LEGISLAÇÃO/MARCOS & Contribuição \\
\hline 1965 & Lei Federal nº 4.771/1965 & Institui o Código Florestal. \\
\hline 1973 & $\begin{array}{l}\text { Secretaria Especial de } \\
\text { Meio Ambiente (Sema), } \\
\text { coordenada pelo Ministério } \\
\text { do Interior (Minter) }\end{array}$ & $\begin{array}{l}\text { Criada a primeira instituição para tratar da temática } \\
\text { ambiental. A agenda da Sema concentrou-se, } \\
\text { principalmente, no problema do controle da poluição } \\
\text { industrial e na gestão de unidades de conservação. }\end{array}$ \\
\hline 1981 & $\begin{array}{l}\text { Política Nacional do Meio } \\
\text { Ambiente (PNMA) - Lei } n^{0} \\
6.938 / 1981\end{array}$ & $\begin{array}{l}\text { Estabelece os princípios, diretrizes, instrumentos e } \\
\text { atribuições para os diversos entes da Federação que } \\
\text { atuam na política ambiental nacional. }\end{array}$ \\
\hline \multirow[t]{2}{*}{1989} & $\begin{array}{l}\text { Instituto Brasileiro do Meio } \\
\text { Ambiente e dos Recursos } \\
\text { Naturais Renováveis (Ibama) } \\
\text { - Lei } \text { n }^{0} 7.735 / 1989\end{array}$ & $\begin{array}{l}\text { Une os órgãos que tratavam a questão ambiental } \\
\text { setorialmente-SuperintendênciadoDesenvolvimento } \\
\text { da Pesca (SUDEPE), Superintendência da Borracha } \\
\text { (SUDHEVEA), Instituto Brasileiro de Desenvolvimento } \\
\text { Florestal (IBDF) e Sema - em torno de um único } \\
\text { órgão federal. }\end{array}$ \\
\hline & $\begin{array}{l}\text { Fundo Nacional de Meio } \\
\text { Ambiente (FNMA) - Lei } n^{\circ} \\
7.797 / 1989\end{array}$ & $\begin{array}{l}\text { Cria o Fundo Nacional de Meio Ambiente para } \\
\text { financiamento da Política Nacional de Meio Ambiente. }\end{array}$ \\
\hline 1990 & $\begin{array}{l}\text { Secretaria de Meio } \\
\text { Ambiente da Presidência } \\
\text { da República (Semam/PR) }\end{array}$ & $\begin{array}{l}\text { Organização da Conferência das Nações Unidas sobre } \\
\text { o Meio Ambiente e o Desenvolvimento (CNUMAD), } \\
\text { conhecida como Rio 92, no Brasil. A conferência } \\
\text { resultou em três importantes convenções ambientais } \\
\text { - biodiversidade, mudanças do clima e desertificação } \\
\text {-, e impulsionou a criação do Ministério do Meio } \\
\text { Ambiente (MMA), no mesmo ano, após a extinção da } \\
\text { Semam/PR. }\end{array}$ \\
\hline 1997 & $\begin{array}{l}\text { Política Nacional de } \\
\text { Recursos Hídricos (PNRH) - } \\
\text { Lei nº 9.433/1997 }\end{array}$ & $\begin{array}{l}\text { Política Nacional de Recursos Hídricos e cria o } \\
\text { Sistema Nacional de Gerenciamento de Recursos } \\
\text { Hídricos. }\end{array}$ \\
\hline
\end{tabular}


1999

Política Nacional de

Educação Ambiental (PNEA)

- Lei no 9.795/1999

Lei $n^{0} 10.165 / 2000$

Lei nº 9.984//2000

2000

Lei nº 9.985/2000

2006 Lei no 11.284/2006

2007

Lei $n^{0} 11.516 / 2007$

2009

Lei nº 12.187/2009

2010

Lei $n^{0}$ 12.305/2010

Conferência Rio+20 - Conferência

das Nações Unidas sobre

Desenvolvimento Sustentável

2012

Lei n $12.651 / 2012$

Institui a Política Nacional de Educação Ambiental e dá outras providências.

Institui a Taxa de Controle e Fiscalização Ambiental (TCFA).

Dispõe sobre a criação da Agência Nacional de Águas (ANA), entidade federal de implementação da Política Nacional de Recursos Hídricos, de coordenação do Sistema Nacional de Gerenciamento de Recursos Hídricos e responsável pela instituição de normas de referência nacionais para a regulação da prestação dos serviços públicos de saneamento básico.

Institui o Sistema Nacional de Unidades de Conservação da Natureza.

Dispõe sobre a gestão de florestas públicas para a produção sustentável; institui, na estrutura do Ministério do Meio Ambiente, o Serviço Florestal Brasileiro (SFB); cria o Fundo Nacional de Desenvolvimento Florestal (FNDF).

Cria o Instituto Chico Mendes para Conservação da Biodiversidade (ICMBio), autarquia federal vinculada ao MMA, com o objetivo de gerenciar todas as unidades de conservação federais.

Institui a Política Nacional sobre Mudança do Clima (PNMC).

Institui a Política Nacional de Resíduos Sólidos (PNRS).

Considerado o maior evento já realizado pelas Nações Unidas. No entanto, o evento, que buscou renovar o compromisso dos países com o princípio do desenvolvimento sustentável, acabou sendo ofuscado por questões econômicas e políticas que mobilizavam as agendas dos países desenvolvidos na época, principalmente a crise econômica dos países europeus.

Institui o Novo Código Florestal e define as áreas de Preservação Permanente. Institui a obrigatoriedade do Cadastro Rural para imóveis rurais. 
Nos anos de 1970 a 1988, foi formado o Sistema Nacional de Meio Ambiente (SISNAMA), pois, com o desenvolvimento do capitalismo e o investimento em processos produtivos, teve início o controle e a regulação do Estado sobre o desenvolvimento e a operação de empreendimentos industriais e de infraestrutura de energia e transporte. Assim, desenvolveu-se o processo de criação dos instrumentos de meio ambiente, comando, controle, fiscalização e licenciamento de atividades poluidoras por meio da avaliação dos impactos nos estudos ambientais.
A Lei 6.938/81 criou a Política Nacional de Meio Ambiente e o Sistema Nacional de Meio Ambiente, deliberando acerca dos seus princípios e funcionamento. A perspectiva da descentralização e interação entre as três esferas de governo foi contemplada no que se refere à inclusão dos estados e municípios, bem como à participação da sociedade civil por meio dos conselhos gestores de políticas públicas. Desta forma, os órgãos ficaram organizados da seguinte forma (Tabela 2):

\section{Tabela 2- Sistema Nacional de Meio Ambiente}

\begin{tabular}{|c|c|}
\hline ÓRGÃO & FUNÇÃO \\
\hline Conselho de Governo & Órgão Superior \\
\hline Conselho Nacional do Meio Ambiente (CONAMA) & Órgão Consultivo e Deliberativo \\
\hline Ministério do Meio Ambiente (MMA) & Órgão Central \\
\hline $\begin{array}{l}\text { Instituto Brasileiro do Meio Ambiente e dos Recursos } \\
\text { Naturais Renováveis (Ibama) e Instituto Chico Mendes } \\
\text { para Conservação da Biodiversidade (ICMBio) }\end{array}$ & Órgãos Executores \\
\hline Órgãos Seccionais & $\begin{array}{l}\text { Órgãos ou entidades estaduais responsáveis pela } \\
\text { execução de programas, projetos e pelo controle e } \\
\text { fiscalização de atividades capazes de provocar a } \\
\text { degradação ambiental }\end{array}$ \\
\hline Órgãos Locais & $\begin{array}{l}\text { Órgãos ou entidades municipais, responsáveis pelo } \\
\text { controle e pela fiscalização dessas atividades nas } \\
\text { suas respectivas jurisdições }\end{array}$ \\
\hline
\end{tabular}

\section{A QUALIDADE DE ENSINO QUE VOCE JÁ GOWHECE.}

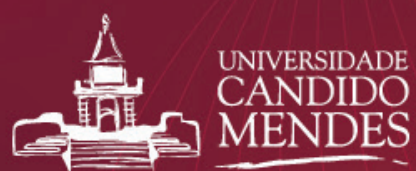

www.ucam-campos.br

22 2726-2400

\section{AGORA!}

口 PRESENCIAL

口 SEMIPRESENCIAL

口 EAD 
Assim, nota-se que a ênfase no processo da gestão ambiental pública volta-se para a implementação de políticas de acordo com o debate internacional na área, tornando o meio ambiente um bem tutelado pelo Estado, tornando-se direito constitucional, conforme 0 art. 225 da Constituição Federal de 1988, no qual "Todos têm direito ao meio ambiente ecologicamente equilibrado, bem de uso comum do povo e essencial à sadia qualidade de vida", sendo dever do Poder Público e da coletividade defendê-lo e preservá-lo.

Segundo Johnston (1995), a proteção do meio ambiente é uma área em que o Estado deve estar presente, porque é seu papel garantir e proteger os direitos humanos, e estes dependem do meio ambiente saudável conforme aponta o direito constitucional supracitado.

\section{A gestão ambiental e a agenda das políticas públicas sob a perspectiva orçamentária}

A Política Nacional de Meio Ambiente - Lei nº 6.938/1981 (BRASIL, 1981) tem por objetivo a preservação, melhoria e recuperação da qualidade ambiental propícia à vida, visando assegurar condições ao desenvolvimento socioeconômico, aos interesses da segurança nacional e à proteção da dignidade da vida humana, atendidos os seguintes princípios:

I - ação governamental na manutenção do equilíbrio ecológico, considerando o meio ambiente como um patrimônio público a ser necessariamente assegurado e protegido, tendo em vista o uso coletivo;

II - racionalização do uso do solo, do subsolo, da água e do ar;

III - planejamento e fiscalização do uso dos recursos ambientais;

IV - proteção dos ecossistemas, com a preservação de áreas representativas;

$\mathrm{V}$ - controle e zoneamento das atividades potencial ou efetivamente poluidoras;

$\mathrm{VI}$ - incentivos ao estudo e à pesquisa de tecnologias orientadas para o uso racional e a proteção dos recursos ambientais;

VII - acompanhamento do estado da qualidade ambiental;

VIII - recuperação de áreas degradadas; (Regulamento);

IX - proteção de áreas ameaçadas de degradação;

$X$ - educação ambiental a todos os níveis de ensino, inclusive a educação da comunidade, objetivando capacitá-la para participação ativa na defesa do meio ambiente (BRASIL, 1981, art. 2, p.1).
Uma das formas de verificar o cumprimento da Política Nacional de Meio Ambiente consiste no monitoramento do orçamento público a partir da função 18 - Gestão Ambiental (categoria funcional) definida pela Portaria no 42/1999 do Ministério do Orçamento e Gestão, a qual estabelece 28 funções baseadas nas competências e finalidades dos entes estatais. A função 18 está dividida nas subfunções: preservação e conservação ambiental, controle ambiental, recuperação de áreas degradadas, recursos hídricos e meteorologia. Estas deveriam ser objeto de ampla divulgação pelo poder público, responsável para acompanhamento e controle por parte da sociedade.

Segundo Garcez (2007), podem surgir conflitos entre o pensamento neoliberal e o papel vital do Estado na promoção e proteção de um meio ambiente saudável e equilibrado, como ocorrido em 2002, quando o Ministério do Meio Ambiente recebeu o menor orçamento de todos os ministérios ao mesmo tempo em que sofreu o maior número de contingenciamento. Isto porque a definição das políticas orçamentárias anuais e a alocação dos recursos ocorrem em um ambiente permeado por disputas políticas, e, não havendo participação da sociedade no processo, as decisões ficam restritas ao Poder Executivo, que elabora o orçamento, e ao Poder Legislativo, responsável pela aprovação (CRUZ; SAUERBRONN; MACEDO, 2013).

Segundo a Lei no 12.527/2011 (BRASIL, 2011), os entes devem disponibilizar as informações geradas pelos sistemas de contabilidade do setor público para garantir a transparência, a fim de que a sociedade possa acompanhar a accountability governamental.

De acordo com Ball (2005), a divulgação, pelo poder público, de informações ambientais geradas pela contabilidade pode colaborar para promover um empowerment da sociedade, inclusive pela tomada de consciência de que os bens ambientais pertencem à coletividade, mas, como são tutelados pelo Estado, devem ser controlados para que sejam geridos de forma adequada.

\section{A gestão ambiental na esfera municipal: análises preliminares acerca do orçamento público de São João da Barra}

0 município de São João da Barra situa-se na Região Norte Fluminense do estado do Rio de Janeiro. Segundo estimativa do IBGE para 2019, possui 36.102 habitantes e densidade demográfica de $71,96 \mathrm{hab} / \mathrm{km}^{2}$, apontada no Censo realizado em 2010. Em relação aos indicadores socioeconômicos, o município registrou, em 2015, o PIB de R\$111.529,404, configurando-se entre os 100 maiores PIB per capita do Brasil. Em relação ao estado do Rio de Janeiro, está entre os quatro primeiros municípios: Porto Real (290 lugar), Itatiaia $\left(38^{\circ}\right)$, São João da Barra $\left(45^{\circ}\right)$ e Mangaratiba (63) (IBGE, 2016). No que se refere ao IDHM, ocupa a $2.642^{\mathrm{a}}$ posição 
em relação aos 5.565 municípios do Brasil, e, ainda, a 76ª no estado do Rio de Janeiro (TCE, 2018).

Quanto aos indicadores que tratam do orçamento público, o município apresentou receita total de R\$ 316,47 milhões em 2017, a 22 ${ }^{\text {a }}$ do estado (em uma comparação que não inclui a capital). Em relação às receitas, vinculadas ao petróleo, registrou $38 \%$ de sua receita corrente total, correspondente a RS 3.379,61 por habitante, $2^{\text {a }}$ colocação no estado; carga tributária per capita de $\mathrm{R} \$ 1.560,08,5^{\mathrm{a}}$ do estado, destas, $\mathrm{R} \$ 42,68 \mathrm{em}$ IPTU (55a posição) e R\$ 1.226,71 em ISS (2 lugar). A despesa total per capita de R\$ 7.848,37 se configura como a $1^{\text {a }}$ do estado, em contraposição a um investimento per capita de RS 19,11, posição de número 73 dentre os 91 demais (TCE, 2018).

Ao observar os programas referentes à Função 18 - Gestão Ambiental ${ }^{5}$, identificamos ações orçamentárias destinadas aos eixos do saneamento básico - esgotamento sanitário, drenagem e resíduos sólidos -, além das comprometidas com a esfera administrativa, ou seja, a manutenção da própria Secretaria de Meio Ambiente (Quadro 2).

\section{Quadro 2: Programas de Trabalho e Ações Orçamentárias referentes à Função 18 - Gestão Ambiental}

\begin{tabular}{|c|c|c|c|c|c|c|}
\hline Programa & Subfunção & Ação Orçamentária & 2014 & 2015 & 2016 & 2017 \\
\hline $\begin{array}{c}024 \text { - Programa } \\
\text { de Saneamento } \\
\text { Ambiental para } \\
\text { Todos }\end{array}$ & $\begin{array}{c}512 \\
\text { SANEAMENTO } \\
\text { BÁSICO URBANO }\end{array}$ & $\begin{array}{l}1088 \\
\text { Construção de Estação } \\
\text { de Tratamento de } \\
\text { Esgoto }\end{array}$ & 300.000 & 300.000 & 300.000 & 2.300 .000 \\
\hline $\begin{array}{l}017 \text { - Preservação } \\
\text { Ambiental Direito e } \\
\text { Dever de Todos }\end{array}$ & $\begin{array}{c}541 \text { PRESERVAÇÃO } \\
\text { ECONSERVAÇÃO } \\
\text { AMBIENTAL }\end{array}$ & $\begin{array}{c}1090 \\
\text { Limpeza de Canais de } \\
\text { Macro e Microdrenagem }\end{array}$ & 1.000 .000 & 1.000 .000 & 1.000 .000 & 4.000 .000 \\
\hline $\begin{array}{l}017 \text { - Preservação } \\
\text { Ambiental Direito e } \\
\text { Dever de Todos }\end{array}$ & $\begin{array}{c}542 \\
\text { CONTROLE } \\
\text { AMBIENTAL }\end{array}$ & $\begin{array}{c}1093 \\
\text { Abertura de Canais de } \\
\text { Macro eMicrodrenagem }\end{array}$ & 300.000 & 300.000 & 200.000 & 2.200 .000 \\
\hline $\begin{array}{l}017 \text { - Preservação } \\
\text { Ambiental Direito e } \\
\text { Dever de Todos }\end{array}$ & $\begin{array}{c}542 \\
\text { CONTROLE } \\
\text { AMBIENTAL }\end{array}$ & $\begin{array}{c}1094 \\
\text { Redee Drenagem de } \\
\text { Águas Pluviais }\end{array}$ & 300.000 & 300.000 & 250.000 & 2.250 .000 \\
\hline $\begin{array}{c}017 \text { - Preservação } \\
\text { Ambiental Direito e } \\
\text { Dever de Todos }\end{array}$ & $\begin{array}{c}542 \\
\text { CONTROLE } \\
\text { AMBIENTAL }\end{array}$ & $\begin{array}{l}1095 \text { Substituição de } \\
\text { Rede Coletora de Esgoto } \\
\text { na sede do município }\end{array}$ & 300.000 & 1.000 .000 & 1.000 .000 & 3.000 .000 \\
\hline $\begin{array}{l}017 \text { - Preservação } \\
\text { Ambiental Direito e } \\
\text { Dever de Todos }\end{array}$ & $\begin{array}{c}122 \\
\text { ADMINISTRAÇÃO } \\
\text { GERAL }\end{array}$ & $\begin{array}{l}1127 \\
\text { Aquisição deEquipamen- } \\
\text { tos-Adm. Geral }\end{array}$ & 20.000 & 20.000 & 20.000 & 20.000 \\
\hline
\end{tabular}


001

Apoio Administrativo

017 - Preservação

Ambiental Direito e

Dever de Todos

017 - Preservação

Ambiental Direito e

Dever de Todos
122

ADMINISTRAÇÃO GERAL

122

ADMINISTRAÇÃO

GERAL

452

SERVIÇOS

URBANOS
2039

Desen. das Atividades da Sec. do Meio Ambiente

5.370 .000

$5.560 .000 \quad 5.800 .000$

6.050 .000

2148

Desenvolvimento de Atividades de Preservação eConservação Ambiental

$\begin{array}{llll}1.300 .000 & 2.750 .000 & 1.400 .000 & 1.500 .000\end{array}$

2040

Limpeza Urbana;

Varrição de Logr:; Ret.

Entulhos; Limpezade

$29.030 .000 \quad 29.030 .000 \quad 29.540 .000 \quad 30.050 .000$

Bueiros 
Ao comparar o orçamento total previsto para os quatros anos da gestão municipal e o destinado à gestão ambiental, identifica-se um percentual entre 8,15\% e 10,29\%, apontando o comprometimento do planejamento municipal com esta política pública (Quadro 3).
A não prioridade dada à gestão ambiental fica evidente quando comparada às despesas totais da execução orçamentária por ano e à executada na Função 18, tendo em vista que 0 percentual situa-se entre 2,19\% e 2,95\% (Quadro 4).

\section{Quadro 3: Relação entre o orçamento total e a gestão ambiental planejada}

\begin{tabular}{|cccc|}
\hline Ano & Orçamento Total Planejado & Função 18 - Gestão Ambiental & Percentual\% \\
\hline 2014 & $\mathrm{R} \$ 398.733 .832,37$ & $\mathrm{R} \$ 37.920 .000,00$ & 9,51 \\
\hline 2015 & $\mathrm{R} \$ 470.545 .795,58$ & $\mathrm{R} \$ 40.260 .000,00$ & 8,56 \\
\hline 2016 & $\mathrm{R} \$ 484.662 .169,45$ & $\mathrm{R} \$ 39.510 .000,00$ & 8,15 \\
\hline 2017 & $\mathrm{R} \$ 499.202 .034,53$ & $\mathrm{R} \$ 51.370 .000,00$ & 10,29 \\
\hline
\end{tabular}

Fonte: Plano Plurianual de São João da Barra (2014-2017), 2019.

\section{Quadro 4: Relação entre o orçamento total e a gestão ambiental executada}

\begin{tabular}{|cccc|}
\hline Ano & Orçamento Total Executado & Função 18 - Executada & Percentual\% \\
\hline 2014 & $\mathrm{R} \$ 389.827 .179,50$ & $\mathrm{R} \$ 11.516 .569,72$ & 2,95 \\
\hline 2015 & $\mathrm{R} \$ 383.510 .888,10$ & $\mathrm{R} \$ 8.912 .175,03$ & 2,32 \\
\hline 2016 & $\mathrm{R} \$ 214.626 .815,40$ & $\mathrm{R} \$ 4.704 .129,85$ & 2,19 \\
\hline 2017 & $\mathrm{R} \$ 251.911 .118,40$ & $\mathrm{R} \$ 6.817 .316,39$ & 2,71 \\
\hline
\end{tabular}

A QUALIDADE DE ENSINO QUE VOCE JÁ CONHECE.

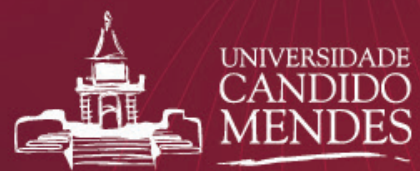

INSCREVA-SE AGORA!

口 PRESENCIAL

口 SEMIPRESENCIAL

口 EAD 
Ao comparar as despesas totais planejadas (Quadro 3) com as executadas (Quadro 4) na Função 18 - Gestão Ambiental, verifica-se que, além do baixo valor destinado a esta política pública, a execução variou entre 11,91\% e 30,37\% (Quadro 5), evidenciando a distância entre o planejamento e a execução, além da baixa prioridade no orçamento municipal.

Quadro 5: Relação entre o orçamento planejado e o executado na

Função 18 - Gestão Ambiental

\begin{tabular}{|cccc}
\hline Ano & $\begin{array}{c}\text { Função 18 - Gestão } \\
\text { Ambiental Planejada }\end{array}$ & $\begin{array}{c}\text { Função 18 - Gestão } \\
\text { Ambiental Executada }\end{array}$ & Percentual\% \\
\hline 2014 & $\mathrm{R} \$ 37.920 .000,00$ & $\mathrm{R} \$ 11.516 .569,72$ & 30,37 \\
\hline 2015 & $\mathrm{R} \$ 40.260 .000,00$ & $\mathrm{R} \$ 8.912 .175,03$ & 22,14 \\
\hline 2016 & $\mathrm{R} \$ 39.510 .000,00$ & $\mathrm{R} \$ 4.704 .129,85$ & 11,91 \\
\hline 2017 & $\mathrm{R} \$ 51.370 .000,00$ & $\mathrm{R} \$ 6.817 .316,39$ & 13,27 \\
\hline
\end{tabular}


Apesar de o município ter apresentado queda na arrecadação em função da crise do petróleo a partir de 2015, os valores planejados e executados evidenciam a baixa prioridade da política, principalmente, quando se analisa o valor da perda da receita total em relação à despesa total (de 3\% a 56\%) e aos gastos com valores planejados e executados com gestão ambiental (69\% e 88\%).

Maia (2006, p.35) aponta como o fato de conciliar crescimento econômico, redução da desigualdade e uso sustentável dos recursos naturais constituem um desafio em escala nacional na busca por mitigar, de forma efetiva e permanente, o quadro de extrema exclusão social. Assim, ao identificar quais são as políticas públicas prioritárias para o município, pode-se conferir que a gestão ambiental ocupou durante os quatros anos de execução orçamentária, respectivamente $6^{a}, 7^{a}$ e $8^{a}$ colocações em detrimento das demais políticas públicas.

\section{Quadro 6: Relação entre o orçamento total executado e o percentual destinado a cada função}

\begin{tabular}{|c|c|c|c|c|c|c|c|c|}
\hline \multirow{2}{*}{ Função } & \multicolumn{2}{|c|}{2014} & \multicolumn{2}{|c|}{2015} & \multicolumn{2}{|c|}{2016} & \multicolumn{2}{|c|}{2017} \\
\hline & $\%$ & Ranking & $\%$ & Ranking & $\%$ & Ranking & $\%$ & Ranking \\
\hline 10 - Saúde & 29,19 & $1^{0}$ & 27,89 & $1^{0}$ & 30,37 & $1^{0}$ & 34,52 & $1^{0}$ \\
\hline 12 - Educação & 18,60 & $2^{0}$ & 21,34 & $2^{0}$ & 21,17 & $2^{0}$ & 19,43 & $2^{0}$ \\
\hline 04 - Administração & 13,65 & $3^{0}$ & 12,92 & $4^{0}$ & 10,08 & $4^{0}$ & 10,19 & $4^{0}$ \\
\hline 15 - Urbanismo & 13,14 & $4^{0}$ & 13,61 & $3^{0}$ & 15,37 & $3^{0}$ & 18,06 & $3^{0}$ \\
\hline 08 - Assistência Social & 8,40 & $5^{0}$ & 7,56 & $5^{0}$ & 5,47 & $5^{0}$ & 2,57 & $7^{0}$ \\
\hline 01 - Legislativa & 5,65 & $6^{0}$ & 2,57 & 70 & 4,69 & $6^{0}$ & 3,64 & $5^{0}$ \\
\hline 18 - Gestão Ambiental & 2,95 & $7^{0}$ & 2,32 & $8^{0}$ & 2,19 & $8^{0}$ & 2,71 & $6^{0}$ \\
\hline 26 - Transporte & 2,68 & $8^{0}$ & 2,91 & $6^{0}$ & 3,22 & $7^{0}$ & 2,30 & $8^{0}$ \\
\hline 06 - Segurança Pública & 1,43 & $9^{\circ}$ & 1,64 & 90 & 1,25 & $11^{\circ}$ & 1,07 & $10^{\circ}$ \\
\hline 02 - Judiciária & 1,27 & $10^{\circ}$ & 1,36 & $10^{\circ}$ & 1,94 & $10^{\circ}$ & 1,87 & 90 \\
\hline 27 - Desporto e Lazer & 1,16 & $11^{\circ}$ & 1,36 & $10^{\circ}$ & 2,13 & $9^{\circ}$ & 1,05 & $11^{\circ}$ \\
\hline 20 - Agricultura & 1,00 & $12^{\circ}$ & 0,99 & $12^{\circ}$ & 0,82 & $13^{\circ}$ & 0,57 & $14^{0}$ \\
\hline 28 - Encargos Especiais & 0,46 & $13^{\circ}$ & 0,53 & $13^{\circ}$ & 0,85 & $12^{\circ}$ & 1,02 & $12^{\circ}$ \\
\hline 13 - Cultura & 0,20 & $14^{\circ}$ & 0,12 & $14^{0}$ & 0,02 & $15^{\circ}$ & 0,02 & $15^{\circ}$ \\
\hline 16 - Habitação & 0,11 & $15^{\circ}$ & 0,08 & $15^{\circ}$ & 0,00 & $17^{0}$ & 0,00 & - \\
\hline 17 - Saneamento & 0,07 & $16^{\circ}$ & 0,01 & $16^{\circ}$ & 0,02 & $16^{\circ}$ & 0,01 & $16^{\circ}$ \\
\hline 14 - Direitos da Cidadania & 0,00 & $17^{\circ}$ & 0,00 & $17^{0}$ & 0,00 & - & 0,00 & - \\
\hline 09 - Previdência Social & 0,00 & - & 0,00 & - & 0,40 & $14^{\circ}$ & 0,98 & $13^{\circ}$ \\
\hline
\end{tabular}


Segundo Sotero (2008) não se pode negar a necessidade de ampliação dos investimentos em meio ambiente, tanto para remediar quanto para evitar a ampliação dos problemas ambientais. Não existem dúvidas quanto à necessidade crescente de recursos financeiros para reverter o passivo ambiental, ainda mais quando há aumento da exploração dos recursos naturais por empreendimentos de grande porte.

De acordo com Kronenberg (2004) há uma correlação negativa entre a abundância de recursos naturais e o crescimento econômico. Segundo ele, entre os países em desenvolvimento, os principais responsáveis pela maldição do recurso natural são os níveis de corrupção e a falta de investimentos em educação. Podemos analisar que a abundância de recursos não é suficiente para assegurar investimentos em políticas públicas capazes de promover condições de vida melhores para a população. Neste contexto, a participação e o controle social sobre elas fazem diferença.

Cabe destacar que o município de São João da Barra possui uma execução orçamentária abaixo do planejado em relação à gestão ambiental. Apesar de o município ter, na última década, aumentado a arrecadação de recursos oriundos da exploração de recursos naturais referentes às rendas petrolíferas e aos impostos provenientes do Complexo Logístico Porto do Açu, ela não retornou para a política pública na mesma proporção.

\section{A guisa da conclusão}

0 estudo aponta a diminuição das despesas municipais para a gestão ambiental, em contraposição ao aumento das receitas oriundas da exploração dos recursos naturais. Desta forma, quando somados os valores das despesas executadas no Plano Plurianual de 2014 a 2017, eles totalizam RS 31.950.190,99, ainda baixos frente às prioridades colocadas pelas políticas públicas e o valor total previsto de R\$ 169.060.000.

A pesquisa deve ser aprofundada em relação aos tipos de despesas municipais a partir dos valores pagos ${ }^{6}$, visto que representa o que de fato é gasto na gestão ambiental pública. Neste sentido, cumpre reforçar a importância de informações nos portais de transparência dos municípios, a fim de potencializar o controle social durante a execução orçamentária, tendo em vista a necessidade de garantir que parte das receitas advindas da exploração dos recursos naturais retornem em forma de políticas públicas por meio da função gestão ambiental à sociedade.

Por fim, as finanças públicas devem deixar de ser um campo privilegiado dos formuladores das políticas públicas para serem apropriadas pela sociedade civil, pois constituem um campo de disputa e uma ferramenta na busca por justiça socioambiental. Assim, não só se participará da inclusão de políticas públicas, como se poderá garantir a sua execução conforme o planejado.

\section{A QUALIDADE DE ENSINO QUE VOCE JÁ CONHECE.}

INSCREVA-SE AGORA!

口 PRESENCIAL

口 SEMIPRESENCIAL

口 EAD

www.ucam-campos.br

22 2726-2400 
BALL, A. Environmental accounting and change in UK local government. Accounting, Auditing \& Accountability Journal, UK, v. 18, n. 3, p. 346373. 2005.

BARROS, M. L. B. A caminho da gestão ambiental. Revista do Tribunal de Contas da União, Brasília, n. 100, p. 34-40, abr.-jun. 2004.

BRASIL. Ministério do Orçamento e Gestão. Portaria nº 42, de 14 de abril de 1999.

Disponível em: ftp://ftp.fnde.gov.br/web/siope/leis/P42_MP0G_14-04-1999.pdf. Acesso em: 01 jul. 2018.

. Ministério do Planejamento, Orçamento e Gestão. Secretaria do Orçamento Federal. Manual Técnico do Orçamento. Brasília. 2018. Disponível em: https://www1.siop.planejamento.gov.br/siopdoc/doku.php/mto:mto_inicial Acessado em 01 de julho de 2018.

INSTITUTO BRASILEIRO DE GEOGRAFIA E ESTATÍSTICA. Disponível em: https://cidades.ibge.gov.br/brasil/rj/sao-joao-da-barra/panorama Acesso em: 10 jan. 2012.

CRUZ, C. F.; MACEDO, M. A. S.; SAUERBRONN, F. F. Um estudo sobre a divulgação de informações de gestão ambiental nas homepages de grandes municípios brasileiros. Revista Contemporânea de Contabilidade, Florianópolis, v. 10, n. 20, p. 161-182, maio-ago. 2013.

DIAS, G. F. Educação Ambiental: princípios e práticas. 9. ed. São Paulo: Gaia, 2004.

GARCEZ, C. A. G. 0 Protocolo de Quioto e o papel do Estado: os casos do Canadá e do Brasil. Interfaces Brasil/Canadá, Rio Grande, v. 7, p. 137-147. 2007.

JOHNSTON, Barbara Rose. Human rights and the environment. Human Ecology, California, v. 23, n. 2, p. 111-118, June 1995. Disponível em: https://link.springer.com/article/10.1007/BF01191645 Acesso em: 18 de dezembro de 2018.

KRONENBERG, T. The curse of natural resources in the transition economies. Economics of Transition. Faculty of Economics and Business Administration, MERIT, University of Maastricht, Netherlands.v.12 (3), p. 399-426, 2004.

MAGRINI, A. Política e gestão ambiental: conceitos e instrumentos. Revista Brasileira de Energia, Itajubá, v. 8, n. 2, 2001. Disponível em: <http:// www.sbpe.org.br>. Acesso em: 26 jun. 2018.

MAIA, Alexandre Gori, Transformações no Mercado de Trabalho e Desigualdade Social. Revista Ciência e Cultura, São Paulo, v. 58, n. 4, out/dez. 2006. Disponível em http://cienciaecultura.bvs.br/pdf/cic/v58n4/a17v58n4.pdf. Acesso em: 20 maio 2019.

MOURA, Adriana M. M. Governança das políticas ambientais no Brasil: construção de um sistema integrado de avaliação. IPEA, v. 1904, p. 1-77, 2013.

PNUMA. Perspectivas do Meio Ambiente Mundial: GEO 3. Brasília: PNUMA/IBAMA, 2002.

QUINTAS, J. S. Educação no processo de gestão ambiental pública: a construção do ato pedagógico. In: LOUREIRO, C. F. B.; LAYRARGUES, P. P.; CASTRO, R. S. (Org.). Repensar a educação ambiental um olhar crítico. São Paulo: Cortez, 2009. p. 33-80.

SÃO JOÃO DA BARRA. Plano Plurianual 2014-2017. Disponível em: https://saojoaodabarra-rj.portaltp.com.br/. Acesso em: 01 jul. 2018.

EVOLUÇÃO DA LEI AMBIENTAL BRASILEIRA. Em discussão. Senado. Disponível: http://www.senado.gov.br/noticias/Jornal/emdiscussao/codigo-florestal/senado-oferece-um-projeto-equilibrado-para-o-novo-codigo-florestal-brasileiro/evolucao-da-lei-ambiental-brasileira.aspx. Acesso em: 9 junho de 2018.

SOTERO, J. P. 0 financiamento público da política nacional de educação ambiental: do veto do artigo 18 às novas estratégias de financiamento. 2008. 236p. Dissertação (Mestrado em Desenvolvimento Sustentável) - Centro de Desenvolvimento Sustentável, Universidade de Brasília, Brasília, 2009.

RIO DE JANEIRO. Tribunal de Contas do Estado do Rio de Janeiro - TCE/RJ. Estudos Socioeconômicos dos Municípios do Rio de Janeiro - São João da Barra. 2018. Disponível em: https://www.tce.rj.gov.br/web/guest/estudos-socioeconomicos1 Acesso em 01 de junho de 2018.

WINDHOLZ, E.; GRAEME, H. A. Conceituando regulação social e econômica: implicações para agentes reguladores e para atividade regulatória atual. RDA, Revista de Direito Administrativo, Rio de Janeiro, v. 264, p. 13- 56, set.-dez. 2013.

A função consiste no maior nível de agregação das diversas áreas de atuação do setor público. Assim, reflete a competência institucional do órgão, como cultura, educação, saúde, defesa, entre outros (MTO, 2018).

A subfunção constitui um nível de agregação imediatamente inferior à função e deve evidenciar a natureza da atuação governamental. De acordo com a Portaria no 42, de 14 de abril de 1999, por meio da matricialidade, é possível combinar as subfunções a funções diferentes daquelas a elas diretamente relacionadas (MTO, 2018).

Importante ressaltar que as funções e subfunções se aplicam ao orçamento público de todos os entes federados, obedecendo o padrão imposto pela Portaria nº 42/1999 do Ministério do Orçamento e Gestão.

4

A pesquisa Produto Interno Bruto - PIB dos Municípios 2010-2015 realizada pelo IBGE, apontou que $25 \%$ do PIB estão concentrados em sete municípios (São Paulo, Rio de Janeiro, Brasília, Belo Horizonte, Curitiba, Porto Alegre e Manaus). 0 maior PIB per capita de 2015, que na média do País chegou a RS 29,323 mil, foi o do município Presidente Kennedy, no Espírito
Santo, com R\$ 513,134 mil. Em seguida, pela ordem, vêm os municípios de Paulínia e Louveira (ambos em São Paulo, com, respectivamente, RS 276,972 mil e RȘ 271, 206); Triunfo (RS); Selvíria (MS); Gavião Peixoto e Ilha Bela (também em São Paulo); São Francisco do Conde (BA); São João da Barra (RJ); e Araporã (MG) (IBGE, 2016).

Conforme descrito na metodologia, a função consiste no maior nível de agregação das diversas áreas de despesa que competem ao setor público. No caso da Função 18 - Gestão Ambiental, reúne todas as despesas na área ambiental.

6 A etapa da despesa referente à execução orçamentária compreende o empenho, a liquidação e o pagamento. 0 empenho cria, para o Estado, a obrigação de pagamento pendente, pois gera uma reserva de dotação orçamentária; a liquidação consiste no reconhecimento do direito adquirido pelo credor de receber, tendo em vista a comprovação da prestação de serviços ou a entrega de produtos: já o pagamento constitui a transferência do recurso ao credor após a liquidação (MTO, 2018). Neste caso, para aferir as despesas públicas, é necessário identificar os pagamentos realizados. 